\title{
The unexpected presence of a huge cystic hygroma with thanatophoric dysplasia type I: a case report
}

\author{
Dr. Mohammed Khairy Ali, ${ }^{1}$ Dr. Sherif A. Shazly, ${ }^{1}$ Dr. Ahmed M. Abbas, ${ }^{1}$ Dr. Mahmoud \\ A. Mahmoud Abd El Aleem, ${ }^{1}$ Dr. Diaa Eldeen M Abd El Aal ${ }^{1}$
}

Keywords: Cystic hygroma, thanatophoric dysplasia

\begin{abstract}
Introduction: The presence of a thin-walled, multicystic structure posterior to the fetal head and neck with an intact vertebral column is known as a cystic hygroma. Thanatophoric dysplasia is the most lethal skeletal dysplasia. Thanatophoric dysplasia (TD) is an autosomal dominant disorder with two phenotypes. TD type I is characterized by a normal shaped skull with bowed femurs and micromelia, while TD type II is characterized by straight femurs with a cloverleaf deformity of the skull and micromelia. We report here a case of thanatophoric dysplasia type I associated with cystic hygroma, this association needs further evaluation.

Case history: A 30 year old woman was referred at 26 weeks of gestation because of marked polyhydramnios. Ultrasonographic examination of the fetus revealed a narrow chest, protuberant abdomen, short curved femur, normal shaped skull with accidentally cystic hygroma were present. No other anomalies were detected. We explained to the patient the nature and severity of the anomaly and the patient preferred the termination of pregnancy. Induction of abortion was done successfully.
\end{abstract}

Conclusion: This case report has highlighted the association between cystic hygroma and thanatophoric dysplasia type $I$. To our knowledge, this is the first report in the literature reporting the association of cystic hygroma and thanatophoric dysplasia type I. We believe that this case is useful for obstetricians and pediatricians. We also highly recommend the genetic evaluation of the fetus and parents.

${ }^{1}$ Women Health Hospital, Assiut, Egypt

\section{Introduction}

Thanatophoric dysplasia (TD) is the most common lethal skeletal dysplasia. Its prevalence is approximately $2 / 100,000$ births. $^{1}$ Thanatophoric is a Greek word and means death bearing. TD is caused by mutations in the Fibroblast Growth Factor Receptor 3 (FGFR3) gene. This mutation leads to different types of skeletal dysplasia. ${ }^{2}$ Children with this condition are usually stillborn or die shortly after birth from respiratory failure; however, small number of individuals have survived into childhood and very few beyond. ${ }^{3}$ Cystic

Please cite this paper as: Ali MK, Shazly SA, Abbas AM, Abdel-Aleem MA, Abdel-Aal DEM. The unexpected presence of a huge cystic hygroma with thanatophoric dysplasia type I: a case report. Proc Obstet Gynecol. 2015;5(3): Article 4 [ 6 p.]. Available from: http://ir.uiowa.edu/pog/ Free full text article.

Corresponding author: Dr. Mohammed Khairy Ali, Women Health Hospital, Assiut, Egypt, m khairy2001@yahoo.com

Financial Disclosure: The authors report no conflict of interest.

Copyright: (c) 2015, Ali et al. This is an open-access article distributed under the terms of the Creative Commons Attribution License, which permits unrestricted use, distribution, and reproduction in any medium, provided the original author and source are credited. 
hygroma is one of the most common anomalies seen in the first trimester. It is characterized by single or multiple congenital lymphatic cysts commonly found in the soft tissues of the neck. ${ }^{4}$ It is highly associated with chromosomal abnormalities; trisomies 21, 18, and 13 are the most prevalent in the first trimester while Turner's syndrome is the most prevalent in the second trimester. ${ }^{5}$

\section{Case history}

A 30 year old woman, gravida 3 , para 2 +0 , presented to the Assiut Women Health Hospital at 26 weeks of gestation. She had had a spontaneous pregnancy with no past history suggestive of infection or medical problems. There was no family history of genetic disorders or positive consanguinity. Ultrasonographic examination of the fetus showed a single living fetus with abnormal fetal morphology. The following ultrasonographic findings were present: a normal shaped head with a large cystic hygroma (Figure 1), a narrow chest with a protuberant abdomen (Figure 2), a short and curved femur, micromelia (Figure 3) and polyhydramnios.

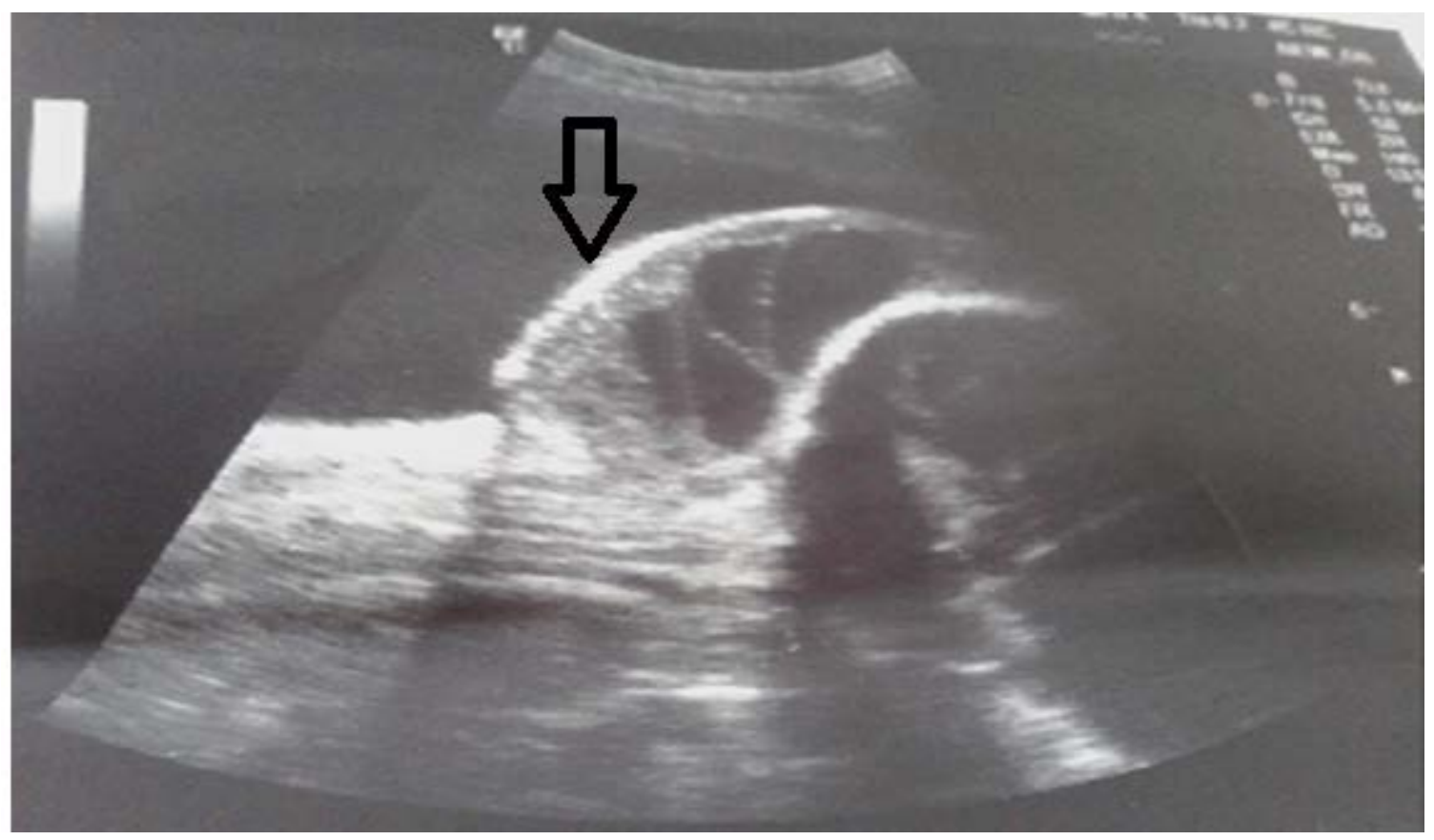

Figure 1: Normal shaped skull with large cystic hygroma (black arrow) around the fetal head

No other anomalies were detected. All these findings suggested the diagnosis of thanatophoric dysplasia type I with cystic hygroma. We explained to the patient the nature and severity of the anomaly. The patient preferred termination of pregnancy. The patient delivered a male fetus weighing $950 \mathrm{~g}$. On inspection, the fetus (Figure 4) had a large head with a soft cystic mass behind the neck suggesting cystic hygroma, frontal bossing, short neck, 
narrow chest, protruded abdomen and short limbs. After discussing with the pediatrician and gynecologist, the fetus was diagnosed to have TD type I. The parent of the fetus refused the postmortem examination.

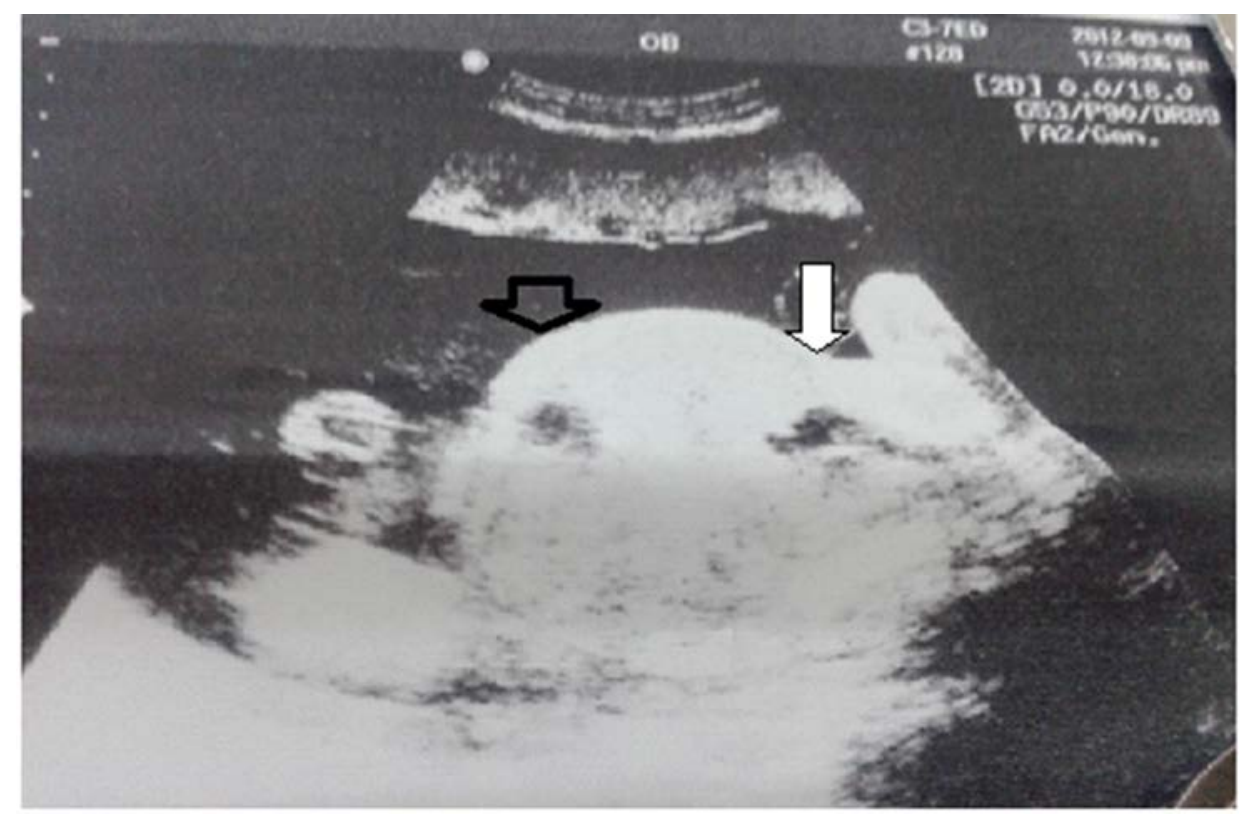

Figure 2: Showing fetus with narrow chest (white arrow) with a protruded abdomen (black arrow)

\section{Discussion}

Thanatophoric dysplasia is a severe lethal skeletal disorder characterized by extremely short limbs. Other features of this condition include a narrow chest, short ribs, and an enlarged head with wide-spaced eyes. There are two forms of thanatophoric dysplasia, type I and type II. Type I thanatophoric dysplasia is characterized by the presence of curved short femur bones and a normal head contour. Type II thanatophoric dysplasia is characterized by straight short femur bones with a skull abnormality called a cloverleaf skull. ${ }^{4}$ Isolated short femur without other anomalies is a marker for fetal aneuploidy; so when a short femur is detected, other long bones should be assessed. ${ }^{6}$ The newborn with thanatophoric dysplasia usually dies shortly after birth from respiratory failure; but some individuals have survived with extensive medical care. ${ }^{7}$ Thanatophoric dysplasia is an autosomal dominant disorder due to the mutation of the FGFR3 gene; so the disorder has not been passed to the next generation because individuals with the mutation rarely survive and have children. This gene is responsible for the development and maintenance of bone and brain tissue. 


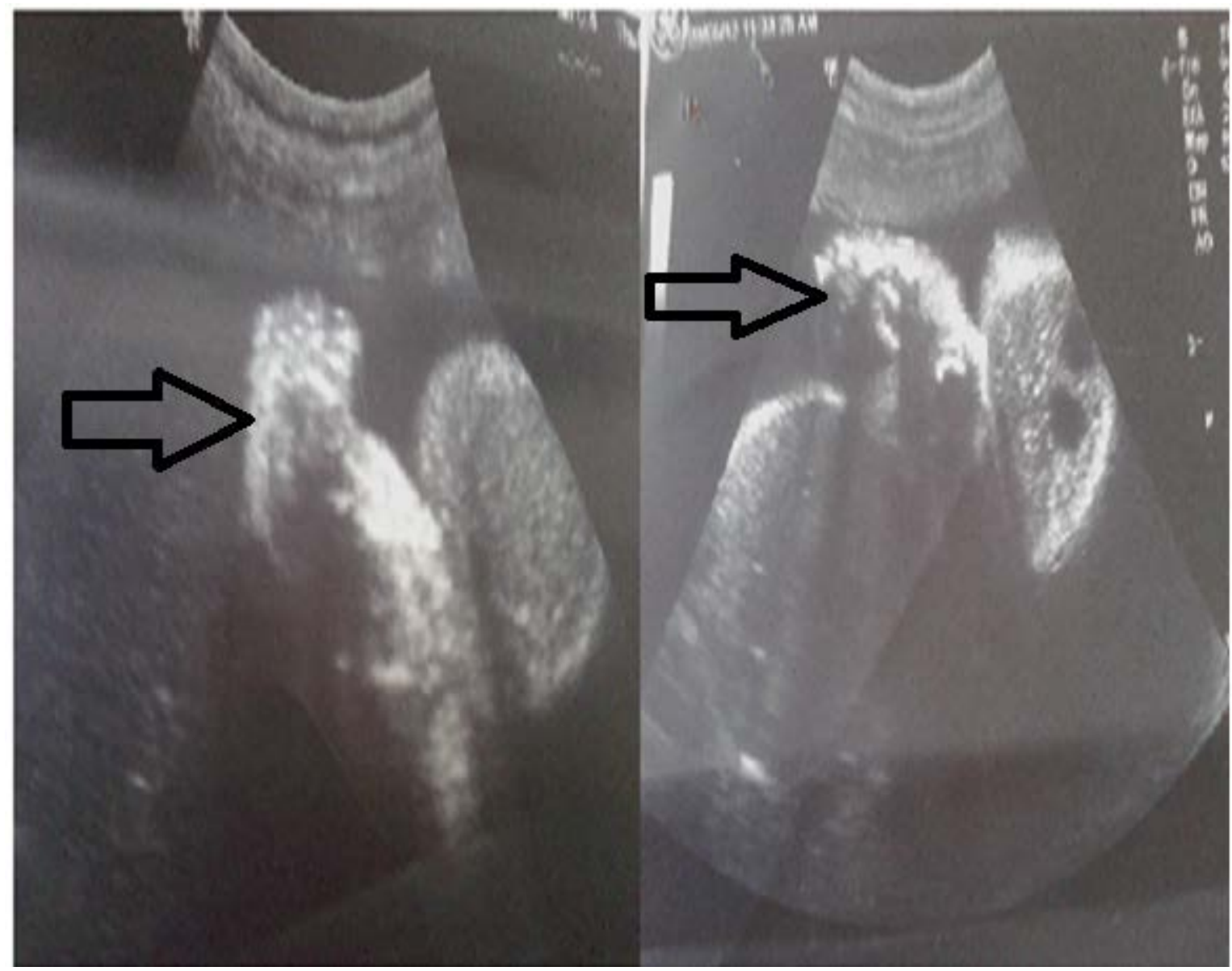

Figure 3: Showing severe micromelia of the fetus (black arrows)

Mutations in the FGFR3 gene lead to severe disturbances in bone growth that are characteristic of thanatophoric dysplasia; but the cause of brain and skin abnormalities associated with thanatophoric dysplasia is still unknown. ${ }^{8}$ Cystic hygroma $(\mathrm{CH})$ is a congenital malformation of the lymphatic system which most commonly presents in the neck, with the most common causes being environmental and genetic factors. ${ }^{9}$ Early diagnosis of TD is important, providing the option of pregnancy termination for affected fetuses. It is important to provide genetic testing and counseling because the mutations involved have been associated with the same phenotype in extremely different diseases; unfortunately, molecular testing was declined by our patient but it is unlikely that either parent is a carrier. The association between aneuploidies and $\mathrm{CH}$ is unexplained, thus it is not clear as it stands leaving it up to the reader to make the connection. In our case; the consent was not provided for molecular confirmation of a diagnosis of TD, but the clinical presentation of the abortus strongly supported this diagnosis while excluding other possible differential diagnoses such as atelosteogenesis 
type II, fibrochondrogenesis, Grebe dysplasia, hypochondrogenesis, lethal osteogenesis imperfect and short ribpolydactyly syndromes. ${ }^{10}$ On the principal point of our case, we can suggest that $\mathrm{CH}$ may be a marker for
TD, but this needs further evaluation. Finally, radiography and a postmortem examination with microscopy of the femur and examination of the brain for temporal dysplasia would be ideal in order to confirm the diagnosis.

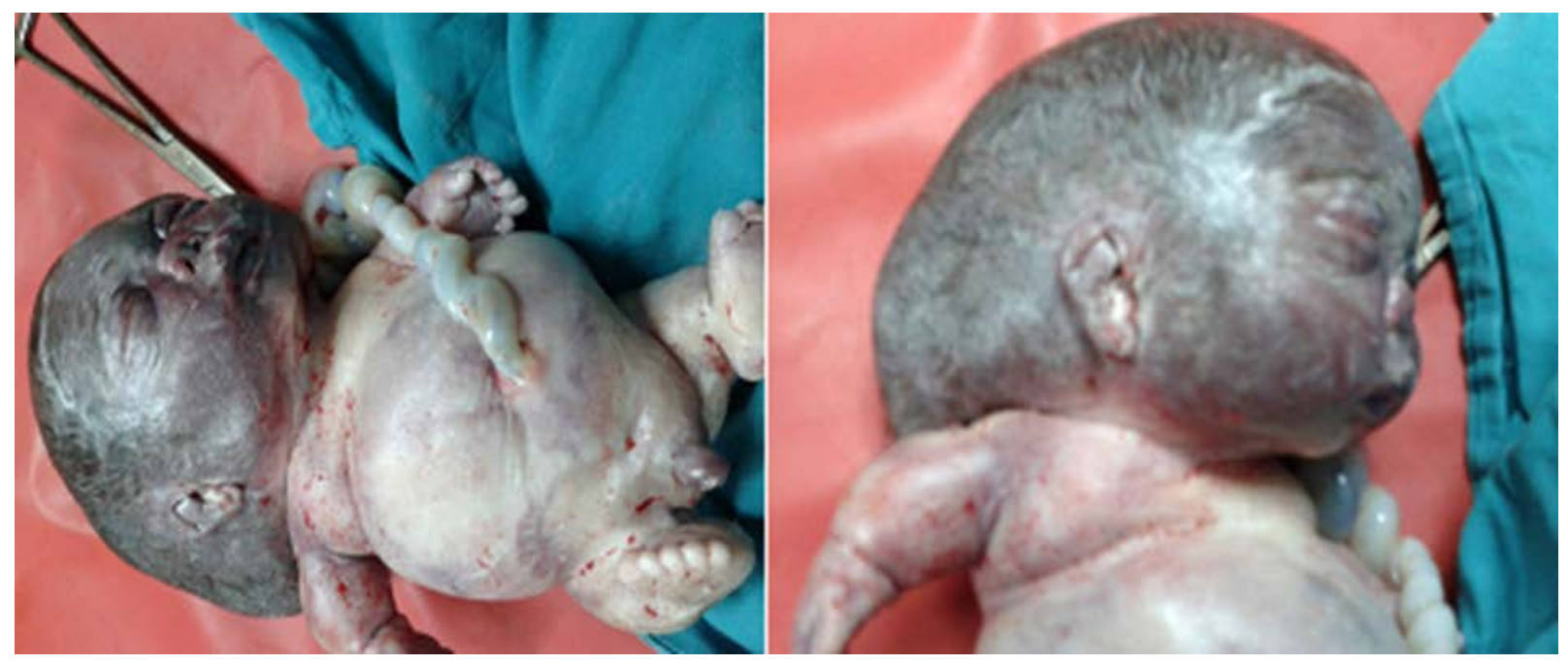

Figure 4: Showing cystic hygroma, sever micromelia, narrow cyst and protruded abdomen of the abortus

\section{Conclusion}

Thanatophoric dysplasia can be easily diagnosed by ultrasound in the second trimester; early diagnosis is important to allow termination of pregnancy when an affected fetus is detected. We report here a case of thanatophoric dysplasia associated with cystic hygroma, this association needs further evaluation.

\section{References}

1. Marquis-Nicholson R, Aftimos S, Love DR. Molecular Analysis of a Case of Thanatophoric Dysplasia Reveals Two de novo FGFR3 Missense Mutations located in cis. Sultan Qaboos Univ Med J. 2013 Feb;13(1):80-7. Epub 2013 Feb 27. http://dx.doi.org/10.12816/0003199 PubMed PMID: 23573386.

2. Naveen NS, Murlimanju BV, Kumar V, Pulakunta T; Jeeyar H. Thanatophoric dysplasia: a rare entity. Oman Med J. 2011 May;26(3):196-7. http://dx.doi.org/10.5001/omj.2011.47 PubMed PMID: 22043415. 
3. Baker KM, Olson DS, Harding CO, Pauli RM. Long-term survival in typical thanatophoric dysplasia type 1 . Am J Med Genet. 1997 Jun 27;70(4):427-36. http://dx.doi.org/10.1002/(SICl)10968628(19970627)70:4<427::AIDAJMG18>3.0.CO;2-J PubMed PMID: 9182787.

4. Ali MK, Abdelbadee AY, Shazly SA, Othman E R. Hydrops fetalis with cystic hygroma: a case report. MEFS. 2012;17(2):134-135. http://dx.doi.org/10.1016/j.mefs.2012.01. $\underline{001}$

5. Ali MK, Abdelbadee AY, Shazly SA . Arthrogryposis with cystic hygroma: a case report. MEFS. 2012;17(3):203205.

http://dx.doi.org/10.1016/j.mefs.2012.01. $\underline{002}$

6. Li D, Liao C, Ma X, Li Q, Tang X. Thanatophoric dysplasia type 2 with encephalocele during the second trimester. Am J Med Genet A. 2006 Jul 1;140(13):1476-7.

http://dx.doi.org/10.1002/ajmg.a.31293

PubMed PMID: 16752380.

7. Ali MK, Shazly SA, Ali AH, Abdelbadee AY, Abbas AM. Ultrasonographic soft markers of aneuploidy in second trimester fetuses. MEFS. 2012;17(3):145-151.

http://dx.doi.org/10.1016/j.mefs.2012.04. $\underline{007}$

8. Sahinoglu Z, Uludogan M, Gurbuz A, Karateke A. Prenatal diagnosis of thanatophoric dysplasia in the second trimester: ultrasonography and other diagnostic modalities. Arch Gynecol Obstet. 2003 Nov;269(1):57-61. Epub 2002 Oct 29. http://dx.doi.org/10.1007/s00404-0020417-1 PubMed PMID: 14605823.
9. Barry S, Allotey J, Brundler AM, Duggal MS. Case report: cystic hygroma. Eur Arch Paediatr Dent. 2012 Dec;13(6):323-5.

http://dx.doi.org/10.1007/BF03320835

PubMed PMID: 23235134.

10. Chen CP, Chern SR, Chang TY, Lin CJ, Wang W, Tzen CY. Second trimester molecular diagnosis of a stop codon FGFR3 mutation in a type I thanatophoric dysplasia fetus following abnormal ultrasound findings. Prenat Diagn. $2002 \quad$ Aug;22(8):736-7. http://dx.doi.org/10.1002/pd.377 PubMed PMID: 12210587. 